Piotr Złotkowski

Uniwersytet Marii Curie-Skłodowskiej w Lublinie

Wydział Humanistyczny

Instytut Filologii Słowiańskiej

tel. 48815372652

e-mail: pzlotko@poczta.umcs.lublin.pl

ORCID ID: https://orcid.org/0000-0001-5777-2114

\title{
Nazwiska historyczne chłopów okolic Brańska na Podlasiu oparte na leksemach zachodzić, przychodzić
}

Słowa kluczowe: antroponimia historyczna, Brańsk, leksemy zachodzić, przychodzić, Podlasie

Badania onomastyczne pogranicza polsko-wschodniosłowiańskiego na Podlasiu mają długą tradycję. Prowadzone są w różnych ośrodkach akademickich w Polsce, m.in. w Białymstoku, Warszawie, Lublinie, Siedlcach. Powstało już wiele opracowań z zakresu antroponimii autorstwa: Z. Abramowicz, E. Bogdanowicz, L. Citko, L. Dacewicz, J. Kuć, M. Sajewicza, B. Tichoniuka, P. Złotkowskiego oraz innych badaczy [Abramowicz 1993, 2009; Bogdanowicz 2000; Citko 2001; Dacewicz 1994, 2001, 2008, 2012, 2014; Kuć 2011; Sajewicz 2013; Tichoniuk 1988, 2000; Złotkowski 2017]. Dotychczasowe badania nad nazewnictwem osobowym tego terenu osadzone były zarówno w płaszczyźnie synchronicznej, jak i diachronicznej.

Celem niniejszego artykułu jest próba ukazania specyfiki i sposobu funkcjonowania antroponimów historycznych określających chłopów okolic Brańska na Podlasiu motywowanych leksemami zachodzić, przychodzić.

Przed przystąpieniem do analizy zebranego materiału onomastycznego należałoby przedstawić dane o frekwencji współczesnych nazwisk tego typu w Polsce. W Stowniku nazwisk współcześnie w Polsce używanych zawierającym materiał onomastyczny z lat 1993-1993 odnotowano 27 nazwisk motywowanych leksemem przychodzić (wraz z jego wschodniosłowiańskim 
odpowiednikiem na -r-). Były to następujące nazwiska (ułożone w porządku alfabetycznym, wraz z liczbą ich użytkowników): Przychoda 114; Przychodko 9; Przychodaj 154; Przychodna 151; Przychodni 111; Przychodnia 97; Przychodniak 123; Przychodny 163; Przychodzen 10; Przychodzen 1235; Przychodzien 1; Przychodzień 421; Przychodzin 5; Przychodziński 13; Przychodzki 1046; Przychodzko 9; Przychodźeń 1; Przychodźko 1; Przychotko 1; Przychoży 1; Przychódzko 4; Przychódźko 1; Prychod 7; Prychoda 11; Prychodicz 3; Prychodko 77; Prychodzicz 5. Łączną liczbę ich nosicieli oszacowano w tym okresie na 3774 osób [Słownik 1994, 565, 589]. Według tego samego źródła w Polsce w latach 90-tych były w użyciu 4 nazwiska utworzone od apelatywu zachodzić. Nosiło je w tym czasie 88 osób. W użyciu były wtedy następujące nazwiska z tej grupy: Zachodna 16; Zachodni 26; Zachodnia 16; Zachodny 30 [Stownik 1994, 392].

Warto również przytoczyć bardziej aktualne dane ze strony internetowej Moi krewni - mapa nazwisk. Według tego źródła, od lat 90-tych do chwili obecnej liczba nazwisk motywowanych leksemem przychodzić zmniejszyła się do 22, zaś liczba ich nosicieli spadła do 3277 osób. Obecnie używane są następujące nazwiska należące do tej podgrupy (obok podajemy liczbę ich użytkowników): Przychoda 94; Przychodko 6; Przychodaj 151; Przychodna 128; Przychodni 116; Przychodnia 85; Przychodniak 102; Przychodny 169; Przychodzen 4; Przychodzen 1285; Przychodzien 1; Przychodzień 487; Przychodzin 1; Przychodzinski 6; Przychodzki 529; Przychodzko 10; Przychotko 1; Przychódzko 1; Prychod 13; Prychoda 8; Prychodko 70; Prychodzicz 10. Nieco inaczej wygląda to $\mathrm{w}$ grupie nazwisk zawierających podstawę motywowaną apelatywem zachodzić. Obecnie ich liczba zwiększyła się do 113, w stosunku do danych z lat 90-tych. Są to następujące nazwiska: Zachodna 19; Zachodni 40; Zachodnia 27; Zachodny 27 [http://www.moikrewni.pl].

Obecność antroponimów historycznych utworzonych od leksemu przychodzić odnotowano również na innych terenach historycznego Podlasia. W Stowniku historycznych nazw osobowych Białostocczyzny zamieszczone są hasła: Przychodzien, Przychoży, Prychoży ${ }^{1}$ [Stownik 1998, 54].

Przed przystąpieniem do analizy onomastycznej zgromadzonego materiału źródłowego nakreślimy krótki opis historyczny, zawierający charakterystykę społeczno-etniczną badanego terenu. Istotne znaczenie dla naszych rozważań ma fakt, że na wschód od Brańska przebiega obecnie pol-

1 Przychodzień: Siemion Przychodzien, Radko Przychodzień 1662, Christophorus Przychodzień, 1672, por. apelatyw przychodzień 'przybyły', Pr(z)ychoży: Macko Przychozy, Roman Przychozy, Szewko Przychozy, Wasko Przychozy, Wawrzys Przychozy 1560, Chilimon Prichożyj 1567, por. apelatyw białoruski. prychoży 'przybysz', pryhoży 'ładny'. 
sko-wschodniosłowiańska granica językowa. W przeszłości miała ona nieco inny przebieg, obejmując swym zasięgiem również miejscowości położone na zachód od miasta. Zasiedlanie okolic Brańska rozpoczęło się w XV wie$\mathrm{ku}$, jednak jeszcze w następnym stuleciu proces ten nie był z całą pewnością zakończony, o czym świadczy powstawanie w tym okresie nowych osad. Zgodnie z ustaleniami historyka J. Wiśniewskiego, napływ ludności na te tereny nastąpił z dwóch kierunków. Obszar ten zasiedlony został bowiem od zachodu przez drobną szlachtę i chłopów pochodzenia mazowieckiego, od wschodu przez chłopów pochodzenia ruskiego, zapewne głównie wołyńskiego [Wiśniewski 1977, 69]. W wyniku tego wokół Brańska powstały osady o różnej strukturze własności ziemskiej, a mianowicie: wsie drobnej szlachty, wsie szlacheckie zasiedlone przez chłopów, wsie chłopskie oraz osady młyńskie starostwa brańskiego.

Wspomniane już przesunięcie granicy językowej na tym terenie spowodowane było procesem stopniowej polonizacji miejscowej ludności. Rozpoczęła się ona już w II połowie XVI wieku i trwała do połowy zeszłego stulecia. Objęła zarówno bojarów, jak i chłopów pochodzenia wschodniosłowiańskiego. Proces polonizacji wiązał się ze zmianą wyznania z prawosławnego na katolickie oraz obrządku z greckiego na rzymski. Jego przebieg miał stałą wewnętrzną dynamikę. Tylko w niektórych miejscowościach (Hodyszewo, Jośki) był bardziej gwałtowny, w czym przypominał zmiany religijno-etniczne zachodzące w XIX wieku i na początku XX stulecia na terenie Podlasia południowego.

Materiał onomastyczny na potrzeby niniejszego opracowania wyekscerpowany został w ramach zakrojonych na większą skalę badań antroponimii historycznej mieszczan i chłopów Brańska i okolic. Zakreślone terytorium badawcze pokrywa się $\mathrm{w}$ przybliżeniu $\mathrm{z}$ obszarem oddziaływania dawnego brańskiego ośrodka grodowego. Wyznaczają je granice dawnych parafii katolickich w Brańsku, Boćkach, Domanowie, Dołubowie, Łubinie Kościelnym, Wyszkach, Topczewie, oraz parafii prawosławnych, a później unickich w Brańsku, Hodyszewie i Maleszach. Na terenie tym istniało w przeszłości 76 punktów osadniczych, z których do dnia dzisiejszego przetrwało 65 osad, w tym 57 odrębnych administracyjnie miejscowości i 8 przysiółków lub części wsi. W prowadzonych badaniach przyjęto założenie, że analizie onomastycznej zostanie poddana w miarę możliwości cała zachowana dla tego obszaru baza źródłowa. W sumie wykorzystano ponad 130 różnego rodzaju materiałów archiwalnych. Podstawowe znaczenie miały zachowane w różnym stopniu księgi metrykalne wspomnianych parafii oraz księgi grodzkie brańskie. Posłużono się również źródłami historycznymi zawierającymi wszelkiego typu spisy ludności, np. rejestr pomiary włócznej starostwa 
brańskiego, rejestry podatku pogłównego, spisy parafialne, inwentarze dóbr oraz inne przydatne materiały źródłowe. Należy zauważyć, że charakteryzuje je na ogół wysoki stopień wiarygodności. Niekiedy jednak zachodziła konieczność dodatkowej weryfikacji pozyskanego materiału badawczego poprzez porównywanie różnych zapisów i ich wzajemną konfrontację [Złotkowski 2017, 13-28].

Wykorzystany tu materiał antroponimiczny pochodzi z okresu od XVI do połowy XIX wieku. Już jego pobieżny ogląd utwierdza nas w przekonaniu, że zawiera on znacznie więcej formacji antroponimicznych motywowanych leksemem zachodzić niż utworzonych od apelatywu przychodzić. Do pierwszej grupy należy zaliczyć następujące antroponimy: Zachodzi / Zachodzy / Zachozy (53 poświadczenia), Zachoda (4 poświadczenia), Zachodzień (1 poświadczenie). W grupie drugiej znalazły się natomiast takie nazwiska historyczne jak: Przychoda / Przygoda (14 poświadczeń), Przychodzy / Przychodzi (5 poświadczeń), Przychodni (1 poświadczenie). Wymienione onimy posłużyły do nominacji antroponimicznej osób pochodzących z 22 miejscowości. Wsie te stanowią łącznie jedną czwartą liczby przebadanych punktów osadniczych. Są to następujące osady: Brańsk, Bodaki, Bodaczki, Brzeźnica, Chojewo, Domanowo, Kiersnowo, Łubin Kościelny, Liza, Łukawica, Markowo, Mień, Nowosady, Oleksin, Osówka, Patoki, Popławy, Sierakowizna, Topczewo, Wólka Zaleska, Zalesie, Załuskie (zob. Skróty nazw miejscowości). Jeśli chodzi o dystrybucję geograficzną wymienionych punktów osadniczych, to są one w miarę równomiernie rozmieszczone na całym badanym obszarze.

W celu przybliżenia specyfiki przebadanego materiału onomastycznego warto zamieścić w tym miejscu wykaz ułożonych w porządku chronologicznym zapisów źródłowych antroponimów opartych na leksemach zachodzić, przychodzić:

Demetrii Przychozi 1648 Br I/B/1 BZ

Laboriosi Gregorii Przychozy 1665 Br I/B/1 PO

Laboriosi Thomae Przygoda 1688 T I/B/2 LI

Laboriosi Nicolai Zachozy 1689 Br I/B/1 BZ

Thomasz Przygoda 1692 KGB 52, k. 83 LI

Honesti Pauli Zachozy 1694 T I/B/2 TP

Honesti Michaelis Zachozy de Strynki 1701 T I/B/2 ZL

Danielis Zachoda 1706 Br I/B/2 BZ

Laboriosi Samuelis Rusin Zachozy biegus $1706 \mathrm{Br}$ I/B/2 PO

Andreae Zachodzien $1706 \mathrm{Br}$ I/B/2 PO, por. Laboriosi Andreae Ex Lithuania

$1702 \mathrm{Br} \mathrm{I} / \mathrm{B} / 2 \mathrm{PO}$

laboriosi Stephani Sienkiewicz Zachodzy 1707 Br I/B/2 BZ 
laboriosi Laurentii Zachoda $1710 \mathrm{Br}$ I/B/2 PO

Laboriosi Stephani Zacheda [!] $1711 \mathrm{Br}$ I/B/2 PO

Theophili Przechozy $1712 \mathrm{Br} \mathrm{I} / \mathrm{B} / 2 \mathrm{BZ}$

Josephi Zachodzy 1712 Br I/B/2 PO

Pauli Zachodzy 1714 Br I/B/2 PO, por. Pauli Vagabundi 1712 Br I/B/2 PO

Christophori Zachozy $1713 \mathrm{Br}$ I/B/2 KI

Procopii Zachozy $1714 \mathrm{Br} \mathrm{I} / \mathrm{B} / 2 \mathrm{PO}$

Andreae Zachodzy $1714 \mathrm{Br} \mathrm{I} / \mathrm{B} / 2 \mathrm{PO}$

Laboriosorum Andreae et Agnetis Zachodzych 1716 T I/B/3 ZL

Laboriosi Martini Przygoda 1717 T I/B/3 LI

laboriosi Pauli Przychodni $1717 \mathrm{Br}$ I/B/2 PO

laboriosi Mathiae Zachodzy $1718 \mathrm{Br} \mathrm{I} / \mathrm{B} / 2 \mathrm{BZ}$

laboriosi Adami Zachodzy $1719 \mathrm{Br} \mathrm{I} / \mathrm{B} / 2 \mathrm{PT}$

laboriosoru[m] Josephi Zachozy $1720 \mathrm{Br}$ I/B/2 OL

Laboriosi Joannis Zachozy $1721 \mathrm{Br} \mathrm{I} / \mathrm{B} / 2 \mathrm{BZ}$

Laboriosorum Joannis Zachozy 1724 Br I/B/2 ZS

Laboriosoru[m] Simonis Przyhody 1725 T I/B/3 LI

Laboriosi Stephani Zachozy $1726 \mathrm{Br} \mathrm{I} / \mathrm{B} / 2 \mathrm{BR}$

Balthazari Przyhoda 1726 T I/B/3 LI

Laboriosor[um] Laurentii et Mariannae Zachoze 1729 Br I/B/2 BZ

Andreae Zachozy $1729 \mathrm{Br} \mathrm{I} / \mathrm{B} / 2 \mathrm{PO}$

Laboriosor[um] Nicolai Zachozy $1729 \mathrm{Br}$ I/B/2 PO

LL Joannis Zachoda $1730 \mathrm{~T}$ I/B/3 LK

Labor[iosorum] Valentini Zachozy 1739 Ł I/B/2 BD

Laboriosor[um] Joannis Zachozy 1739 Ł I/B/2 LS

Laboriosorum Gregorii Zachodzy 1743 T I/B/5 LI; LL Gregorii et Theressiae

Przyhodow 1752 T I/B/5 LI; Laboriosor[um] Gregorii Przyodzi [!] 1754

$\mathrm{T} \mathrm{I} / \mathrm{B} / 5 \mathrm{LI}$

Laboriosorum Adalberti Zachodzy 1745 T I/B/5 LI

Laboriosor[um] J[o]annis et Agathiae Zachodzych 1745 Dm I/B/1 MN

Laboriosor[um] Benedicti Zachodzy 1745 T I/B/5 OS

Laboriosorum Onisko Olszewski Zachozy 1746 七 I/B/2 LB

Laboriosor[um] Martini Zachodzi 1751 T I/B/5 OS

LL Casimiri et Martiannae Przychodow 1752 T I/B/5 LI

LL Gregorii Zachodzy 1752 T I/B/5 LK

Lab[orio]s[o]r[um] Jacobi et Marciannae Zachodzych 1754 Dm I/B/1 DM

LL Francisci Mazurek Zachodzy 1755 T I/B/5 WZ

Lab[orio]sor[um] Josephi et Dorotheae Zachodzych 1756 Dm I/B/1 DM

Laboriosor[um] Gregorii et Cristinae Zachodzich 1756 Dm I/B/1 DM

Laboriosorum Joannis et Marcellae Zachodzych 1758 Dm I/B/1 PT

Laboriosor[um] Alexandri Zachozy 1763 Ł I/B/2 BM

Lab[oriosorum] Mathaei Zachodzi 1764 Dm I/B/1 DM

Laboriosi Michaelis Zachod[...] 1767 Ł I/B/4 NO

roboczego Grzegorza Przygody 1771 H LB I LI 
Roboczego Pawła Przygody 1772 H LB I LI

H[onestorum] Leonis et Annae Zachodzych 1773 Ł I/B/4 CH

Lab[oriosorum] Adalberti Zachodzi 1774 Dm I/B/1 MN

Honestor[um] Stephani et Annae Zachodzych Szewcow 1777 Ł I/B/4 CH

LL Lucae Zachodzi 1777 Dm I/B/1 MR; Lab[oriosi] Lucae Zachodzy 1780 Dm

$\mathrm{I} / \mathrm{B} / 1 \mathrm{MR}$

Laboriosor[um] Pauli Zachodzi 1777 Dm I/B/1 DM

Lab[oriosorum] Fedori et Mariannae Zachodzych 1778 Dm I/B/1 DM

Lab[oriosorum] Adalberti Zu[...]wski Zachodzy 1779 Dm I/B/1 MR

Lab[oriosorum] Valentini et Luciae Zachodzych 1782 Dm I/B/2 DM; Lab[oriosorum] Valentini et Mariannae Przychodzych 1784 Dm I/B/2 DM

Lab[orio]sor[um] Andreae et Rosaliae Zachodzych 1783 Dm I/B/2 MR

Lab[oriosorum] Joannis et Mariannae Zachodzych 1783 Dm I/B/2 DM

Lab[orio]sor[um] Stanislai et Caeciliae Zachodzych 1783 Dm I/B/2 MN

H[ones]tor[um] Gregorii et Theodor[a]e Pruszewiczow Zachodzych 1785 Dm

$\mathrm{I} / \mathrm{B} / 2 \mathrm{MN}$

Lab[orio]sor[um] Stanislai Zachodzy 1787 Dm I/B/2 DM

Lab[orio]so[rum] Josephi et Angelae Mikołayczukow Zachodzych 1789 Dm

$\mathrm{I} / \mathrm{B} / 2 \mathrm{DM}$

Laboriosorum Baltazari et Rosaliae Zachodzych 1795 Dm I/B/2 DM

Grzegorzowi Zachodzemu 1799 T I/B/8 LI

Eukaszowi Zachodzemu 1799 T I/B/8 ZL

Jakóbowi Przygodzie Poddan[emu] 1800 T I/B/8 LI

Laborioso Joanni Przychodzy 1805 Dm I/B/2 MN

Ucz[ciwemu] Antoniemu Przygodzie 1811 T/B WM3 LI

Uczciwemu Franciszkowi Przygodzie 1814 T/B WM6 LI;

Laboriosorum Petri et Feliciannae Laszczewska Przygodow 1816 T/B WM8 LI

Piotr Przychoda 1843 T III/S/1 LI

Jak wynika z powyższego zestawienia przebadany materiał antroponimiczny zawiera jednostki językowe, które posłużyły do identyfikacji antroponimicznej 77 osób (mężczyzn). Należy wyjaśnić, że liczba ta jest niższa od ilości wszystkich wystąpień interesujących nas nazw w źródłach, niniejsze zestawienie nie uwzględnia bowiem tożsamych zapisów identyfikujących te same osoby. Wynik ten należy interpretować w kontekście kompletności zachowania bazy źródłowej. Wydaje się jednak, że nie wpłynęła ona znacząco na osiągnięty rezultat, a tym samym nie spowodowała zafałszowania obrazu przebiegu procesu nazwiskotwórczego.

Najwcześniejsze chronologicznie poświadczenie onimu zawierającego interesujący nas leksem pochodzi z 1648 roku. Identyfikuje ono Dymitra Przychozego, mieszkańca wsi Brzeźnica, por. Demetrii Przychozi 1648 $\mathrm{Br} \mathrm{I} / \mathrm{B} / 1 \mathrm{BZ}$. O tym, że tego typu formacje antroponimiczne używane były na badanym obszarze jeszcze w połowie XIX wieku, świadczy zapis 
z 1843 roku, odnoszący się do Piotra Przychody, chłopa z miejscowości Liza, por. Piotr Przychoda 1843 T III/S/1 LI. Przytoczone przykłady skłaniają nas do wniosku, że wskazany sposób nominacji mógł funkcjonować w ramach badanej wspólnoty lokalnej, co najmniej w ciągu dwóch stuleci. Niemniej jednak, jego dynamika była różna w poszczególnych podokresach. I tak, dla I połowy XVII wieku odnotowano tylko jedno poświadczenie, dla II połowy XVII wieku - 5, dla I połowy XVIII wieku - 37, dla II połowy XVIII wieku - 32, dla I połowy XIX wieku - 6 poświadczeń. Można zatem zaryzykować twierdzenie, że formacje antroponimiczne motywowane leksemem zachodzić, przychodzić były szczególnie popularne w okolicach Brańska w XVIII stuleciu. Począwszy od przełomu XVIII i XIX wieku ten sposób nominacji stawał się mniej popularny i stopniowo zanikał. Świadczy o tym chociażby fakt, że obecnie na tym terenie jedynie we wsi Kadłubówka występuje nazwisko Przychodzien, a w sąsiedztwie, ale już poza obszarem badań w miejscowości Knorydy notowane jest nazwisko Przychodzeń.

Zasadne staje się więc pytanie, dlaczego owe formacje antroponimiczne zanikły i w jaki sposób do tego doszło. Odpowiedź nie wydaje się skomplikowana. Można przypuszczać, że onimy oparte na leksemach zachodzić, przychodzić służyły do identyfikacji osób, które przybyły z innych miejscowości, a więc nowych w środowisku wiejskim. Warto zwrócić uwagę na fakt, że pole semantyczne apelatywów, które motywują tego typu antroponimy zawiera w sobie pojęcie ruchu (mobilności). Wydaje się również, że interesujące nas nazwy osobowe konotowały element obcości. Przykładowo, jeśli człowiek „z zewnątrz" osiedlał się w danej miejscowości, to z czasem dochodziło do skrócenia dystansu między nim a osiadłymi mieszkańcami, w wyniku czego społeczność lokalna stopniowo oswajała się z obcym. Jest to ogólnie znane zjawisko społeczne. Proces ten doprowadził zapewne do wyparcia nazw osobowych zawierających leksemy zachodzić, przychodzić z lokalnego mikrosystemu antroponimicznego. Można w tym miejscu postawić pytanie, czy badacz antroponimii może odtworzyć przebieg tego procesu i czy ma do tego narzędzia?

Wydaje się, że kluczowe znaczenie dla wyjaśnienia tej kwestii mają antroponimiczne formuły identyfikacyjne zawierające obok antroponimu motywowanego leksemem zachodzić, przychodzić także inną nazwę osobową. $\mathrm{W}$ zbadanym materiale odnotowano 5 takich formul. Oto one:

[Samuel] Zachozy: Biegus: Rusin 1706 PO

[Onisko] Zachozy: Olszewski $1746 \mathrm{LB}$

[Franciszek] Zachodzy: Mazurek $1755 \mathrm{WZ}$

[Stefan] Zachodzy: Szewc $1777 \mathrm{CH}$

[Wojciech] Zachodzy: Zu[...]wski $1779 \mathrm{MR}$ 
Oprócz wymienionych zestawień warto zwrócić uwagą na 15 innych formuł antroponimicznych, które również zawierają nazwę osobową opartą na leksemie zachodzić, przychodzić. W przeciwieństwie jednak do formacji przedstawionych wcześniej, mają one nieco inny charakter, zawierają bowiem nazwy, które nie współwystępują równocześnie. Formuły tego typu należy traktować jako zestawienia różnych nazw identyfikujących te same osoby na przestrzeni kilku lub kilkunastu lat. Wyodrębnione w ten sposób zestawienia zawierają od 2 do 5 elementów. Przedstawmy je, uporządkowane według kolejności chronologicznej poświadczenia jednego z członów:

[Daniel] Zachoda: Kacałap: Oleksiuk 1705-1712 BZ

[Stefan] Zachodzy: Sienkiewicz/Szynkiewic 1707-1718 BZ

[Wawrzyniec] Zachoda: Koleśnik 1710-1712 PO

[Adam] Zachodzy: Lachowicz: Lasiuk 1716-1726 PT

[Kazimierz] Przychoda: Olkowicz: Sikoic 1743-1753 LI

[Wojciech] Zachodzy: Kudłak: Lesuicin: Lesiuta: Leścioła 1743-1753 LI

[Benedykt] Zachodzy: Banach: Chojnicki 1745-1749 OS

[Grzegorz] Zachodzy: Lojkowski 1751-1755 LK

[Michał] Zachodzy: Koreniuk: Romaniuk 1765-1771 NO

[Andrzej] Zachodzy: Samojto/Samujto: Zabłocki 1774-1790 MR

[Pawel] Zachodzi: Szostakiewicz 1777-1779 DM

[Stanisław] Zachodzy: Podstanczy 1783-1795 MN

[Grzegorz] Zachodzy: Pruszewicz 1785-1790 MN

[Józef] Zachodzy: Mikołajczuk 1789-1797 DM

[Baltazar] Zachodzy: Kazimierczuk 1795-1803 DM

Należy zauważyć, że wymienione formuły posłużyły do identyfikacji antroponimicznej około jednej czwartej osób poświadczonych w zgromadzonym materiale źródłowym. Pozostałe trzy czwarte ludności zidentyfikowano przy pomocy pojedynczych antroponimów. Wydaje się, że dane te wskazują na nieustabilizowanie formalno-strukturalne lokalnego systemu antroponimicznego, przynajmniej do końca XVIII wieku. Współwystępowanie dwu lub więcej nazw osobowych jako części składowych zestawień antroponimicznych świadczy również o tym, że do tego czasu nazwiska chłopów okolic Brańska nie były jeszcze ostatecznie ustalone i spetryfikowane. Można więc zaryzykować stwierdzenie, że lokalny mikrosystem nazwisk nie był jeszcze w tym okresie zamknięty.

Podsumowując, trzeba zauważyć, że antroponimy historyczne chłopów okolic Brańska na Podlasiu oparte na leksemach zachodzić, przychodzić stanowiły zauważalny element lokalnego systemu nazewniczego. Szczególne na- 
tężenie ich występowania miało miejsce w XVIII wieku. Nazwy osobowe tego typu mogły stanowić pojedynczy onimiczny element identyfikacyjny osoby albo były częścią zestawień antroponimicznych. Należy również dodać, że obecnie na badanym obszarze nazwiska tego typu są niezwykle rzadkie.

\section{Źródła}

AGAD Warszawa:

KGB 52, Księga grodzka brańska z 1691 i 1712 r.

AP Hodyszewo:

H LB I, Księga chrztów par. unickiej Hodyszewo z l. 1759-1801

AD Drohiczyn:

Br I/B/1, Księga chrztów par. Brańsk z l. 1644-1701

Br I/B/2, Księga chrztów par. Brańsk z l. 1702-1734

Dm I/B/1, Księga chrztów par. Domanowo z 1. 1743-1780

Dm I/B/2, Księga chrztów par. Domanowo z l. 1780-1812

Ł I/B/2, Księga chrztów par. Łubin z 1. 1725-1766

Ł I/B/4, Księga chrztów par. Łubin z 1. 1766-1790

T I/B/2, Księga chrztów par. Topczewo z l. 1682-1715

T I/B/3, Księga chrztów par. Topczewo z l. 1716-1730

T I/B/5, Księga chrztów par. Topczewo z l. 1743-1755

T I/B/8, Księga chrztów par. Topczewo z l. 1793-1800

T III/S/1, Księga spisu parafialnego par. Topczewo z $1843 \mathrm{r}$.

AP Białystok:

Mikrofilmy akt metrykalnych par. rzymskokatolickich archidiakonatu białostockiego z lat 1808-1864:

T/B WM3, Akta chrztów par. Topczewo z l. 1810-1811

T/B WM6, Akta chrztów par. Topczewo z l. 1813-1814

T/B WM8, Akta chrztów par. Topczewo z l. 1815-1816

\section{Literatura}

Abramowicz Z., 1993, Imiona chrzestne białostocczan w aspekcie socjolingwistycznym (lata 1885-1995), Białystok.

Abramowicz Z., 2010, Antroponimia Żydów białostockich, Białystok.

Bogdanowicz E., 2000, Osiemnastowieczne nazewnictwo osobowe południowej Biatostocczyzny, Białystok, (wydruk komputerowy).

Citko L., 2001, Nazewnictwo osobowe pótnocnego Podlasia w XVI w., Białystok.

Dacewicz L., 1994, Nazewnictwo kobiet $w$ dawnym powiecie mielnickim (XVIXVII), Białystok.

Dacewicz L., 2001, Antroponimia Białegostoku w XVII-XVIII wieku, Białystok.

Dacewicz L., 2008, Antroponimia Żydów Podlasia w XVI-XVIII wieku, Białystok. 
Dacewicz L., 2012, Antroponimia Tatarów litewsko-polskich w przekroju historycznym, Białystok.

Dacewicz L., 2014, Historia nazwisk na kresach pótnocno-wschodnich Rzeczpospolitej (XVI-XVIII w.), Białystok.

Kuć J., 2011, Antroponimia pogranicza podlasko-mazowieckiego (na podstawie ksiag metrykalnych z Mokobód), Siedlce.

Sajewicz M., 2013, Nazwiska patronimiczne z formantem -uk w powiecie hajnowskim na Białostocczyźnie na tle ogólnopolskim, Lubin.

Stownik nazwisk wspólcześnie w Polsce używanych, 1993, 1994, wyd. Rymut K., t. 7, 10, Kraków.

Stownik historycznych nazw osobowych Białostocczyzny, 1998, red. Abramowicz Z., Citko L., Dacewicz L., t. 2, Białystok.

Tichoniuk B., 1988, Antroponimia potudniowej Białostocczyzny w XVI wieku, Opole.

Tichoniuk B., 2000, Imiona $i$ ich formy na pograniczu polsko-biatoruskim od XVI wieku do roku 1839, Zielona Góra.

Wiśniewski J., 1977, Osadnictwo wschodniej Białostocczyzny - geneza, rozwój oraz zróżnicowanie i przemiany etniczne, „Acta Baltico-Slavica”, nr 11, s. 7-80.

Złotkowski P., 2017, Antroponimia historyczna mieszczan i chłopów Brańska i okolic $w$ ujęciu statycznym $i$ dynamicznym, Lublin.

\section{Skróty nazw miejscowości}

BD Bodaki; BM Bodaczki; BR Brańsk; BZ Brzeźnica; CH Chojewo; DM Domanowo; KI Kiersnowo; LB Łubin Kościelny; LI Liza; LK Łukawica; LS Sierakowizna; MN Mień; MR Markowo; NO Nowosady; OL Oleksin; OS Osówka; PO Popławy; PT Patoki; TP Topczewo; WZ Wólka Zaleska; ZL Zalesie; ZS Załuskie

\section{HISTORICAL SURNAMES OF THE PEASANTRY AROUND BRAŃSK IN THE PODLASIE REGION BASED ON LEXEMES ZACHODZIĆ, PRZYCHODZIĆ}

S U M M A R Y

This article discusses the historical anthroponyms of the peasantry around Brańsk in the Podlasie region based on lexemes zachodzić, przychodzić. In this research were used the personal names excerpted from the historical records (16th-mid-19th century). It was established that in the area personal names of this type become gradually less popular and finally disappeared from the anthroponymic system. The purpose of this study is to investigate this process. 